\title{
NMR of glycogen in exercise
}

\author{
Thomas B. Price ${ }^{1 *}$, Douglas L. Rothman ${ }^{1}$ and Robert G. Shulman ${ }^{2}$ \\ ${ }^{1}$ Department of Diagnostic Radiology, Yale University School of Medicine, New Haven, CT 06510, USA \\ ${ }^{2}$ Department of Molecular Biophysics and Biochemistry, Yale University, New Haven, CT 06510, USA
}

\begin{abstract}
Natural-abundance ${ }^{13} \mathrm{C}$ NMR spectroscopy is a non-invasive technique that enables in vivo assessments of muscle and/or liver glycogen concentrations. Over the last several years, ${ }^{13} \mathrm{C} N M R$ has been developed and used to obtain information about human glycogen metabolism with diet and exercise. Since NMR is non-invasive, more data points are available over a specified time course, dramatically improving the time resolution. This improved time resolution has enabled the documentation of subtleties of muscle glycogen re-synthesis following severe glycogen depletion that were not previously observed. Muscle and liver glycogen concentrations have been tracked in several different human populations under conditions that include: (1) muscle glycogen recovery from intense localized exercise with normal insulin and with insulin suppressed; (2) muscle glycogen recovery in an insulin-resistant population; (3) muscle glycogen depletion during prolonged low-intensity exercise; (4) effect of a mixed meal on postprandial muscle and liver glycogen synthesis. The present review focuses on basic ${ }^{13} \mathrm{C}$ NMR and gives results from selected studies.
\end{abstract}

Muscle metabolism: NMR: Glycogen: Exercise: Insulin

With the development of human ${ }^{13} \mathrm{C}$ NMR it is now possible to measure glycogen concentrations in individual muscles without resorting to traditional invasive techniques. The musculature has long been an organ of intense interest in the exercise science community. During exercise muscle glycogen levels are reduced according to the type of exercise, and reflect variables such as workload and rate of contraction (Ivy et al. 1987; Price et al. 1991, 1994a; Robergs et al. 1991). Intense exercise can deplete the bulk of glycogen in a muscle in as little as $10 \mathrm{~min}$ (Price et al. $1994 a$ ). When exercise ceases, the exercised muscles then resynthesize glycogen at a rate that is influenced by the concentration of glycogen remaining within the muscle (Price et al. 1994a). ${ }^{13} \mathrm{C}$ NMR provides non-invasive and continuous assessment of muscle glycogen concentrations and their dependence on diet and exercise.

Until recently, information about the complicated patterns of muscle glycogen balance and its relationship with exercise has only been available by using needle biopsies that could measure muscle glycogen concentrations (Harris et al. 1974; Dietrichson et al. 1987). While biopsies provided the original broad outline of muscle glycogen metabolism, the number and frequency of measurements and the sampling of only a small volume in a non- homogeneous tissue were limitations of the method (Taylor et al. 1992). With the advent of in vivo natural-abundance ${ }^{13} \mathrm{C}$ NMR it has become possible to obtain glycogen measurements non-invasively following depletion, with better time resolution, repeatability, and somewhat better precision (Taylor et al. 1992; Price et al. 1994a). Using ${ }^{13} \mathrm{C}$ NMR an extremely rapid separate phase of glycogen resynthesis was distinguished from the slower subsequent resynthesis. (Price et al. 1994a). Although the qualitative features of an initial rapid rate of resynthesis that was not insulin sensitive, followed by a slower insulin-dependent synthesis had been outlined by biopsy measurements (Maehlum et al. 1977), the quantitative separation of the rates into two periods, as shown by the ${ }^{13} \mathrm{C}$ NMR, provided a more distinct interpretation.

However, ${ }^{13} \mathrm{C}$ NMR is not without its drawbacks, that include the availability of expensive well-maintained equipment, and the inability to distinguish between fibre types (Taylor et al. 1992). When performed in natural abundance, signal : noise becomes an issue with ${ }^{13} \mathrm{C}$ NMR. Several hundred dollars-worth of enriched glucose can increase ${ }^{13} \mathrm{C}$ NMR signal by one order of magnitude above natural abundance in a normal human study. In addition, these NMR methods are confined to measuring the

Abbreviations: G6P, glucose-6-phosphate; NIDDM, non-insulin-dependent diabetes mellitus; RF, radiofrequency. *Corresponding author: Dr Thomas B. Price, fax +1 203785 6534, email price@ boreas.med.yale.edu 
concentration of muscle metabolites including glycogen (Avison et al. 1988), glucose-6-phosphate (G6P; Rothman et al. 1992), creatine phosphate, inorganic phosphate (Gadian et al. 1979) and lactate (Pan et al. 1989), while enzymic rates must be calculated from changing concentrations in label. The complementary abilities of NMR and biopsy methods create opportunities to combine the techniques, and to gain a deeper understanding of muscle metabolism during exercise and recovery.

A question often asked about the ${ }^{13} \mathrm{C}$ NMR measurement of glycogen is why it is performed at only a small number of laboratories. The primary limitation in making the measurement more widespread is that most standard magnetic resonance imaging and spectroscopy systems are unable to perform the glycogen measurement without hardware and software modifications. Although it is beyond the scope of the present review to describe this equipment in detail, we provide a short list here of the additional equipment required. The ${ }^{13} \mathrm{C}$ NMR glycogen resonance is detected by measuring the induced voltage in a radiofrequency $(\mathrm{RF})$ coil from the time-varying magnetic field emitted by the glycogen ${ }^{13} \mathrm{C}$ nuclei. The resonance frequency depends both on the nucleus and the chemical environment of the nucleus. A standard clinical magnetic resonance system is unable to receive the glycogen RF signal because it is tuned only to receive the frequency of the ${ }^{1} \mathrm{H}$ nuclei in water. In order to convert a magnetic resonance imaging system to be able to measure glycogen, an additional receiver channel is required tuned to the ${ }^{13} \mathrm{C}$ frequency, including an RF coil tuned to the ${ }^{13} \mathrm{C}$ nuclei. A further complication is that, due to interactions with bound ${ }^{1} \mathrm{H}$ nuclei, the resonance of $\left[1-{ }^{13} \mathrm{C}\right]$ glycogen is split into two frequencies, which complicates detection. To eliminate this interaction, referred to as J-coupling, it is necessary to apply energy at the resonance frequency of the bound glycogen ${ }^{1} \mathrm{H}$ nuclei (decoupling) during the acquisition of the ${ }^{13} \mathrm{C}$ signal. This energy must be applied with a separate RF coil tuned to the ${ }^{1} \mathrm{H}$ frequency. Furthermore, an additional RF amplifier and RF frequency generator is required to produce the RF energy transmitted from the decoupling coil. The energy applied at the ${ }^{1} \mathrm{H}$ frequency will introduce noise into the ${ }^{13} \mathrm{C}$ receiver unless care is taken with appropriate RF filters to block the energy from reaching the ${ }^{13} \mathrm{C}$ receiver. Once the appropriate hardware and software is available the primary limitations on the accuracy of the NMR measurement are sensitivity, and calibration against an external glycogen standard. Calibration of the glycogen measurement requires that the signal obtained from the muscle be compared with the signal obtained from a solution of glycogen that encompasses the same volume as the muscle. If the muscle is smaller than the receiving field of the ${ }^{13} \mathrm{C} \mathrm{RF}$ coil, it may be difficult to make an accurately-shaped standard. An alternative is to use localized spectroscopy which selects a volume defined independently of the receiving field of the coil (Rothman et al. 1990). The disadvantage of using localization is that the programming of the system to perform these experiments is more complicated.

Methods of ${ }^{13} \mathrm{C}$ NMR acquisition and data processing have been described in detail in a number of publications (Avison et al. 1988; Jue et al. 1989; Price et al. 1991, 1994a; Taylor et al. 1992, 1993, 1996). Briefly, in order to obtain a
${ }^{13} \mathrm{C}$ NMR spectrum a simple proton decoupled pulseacquire pulse programme is used. A surface coil RF probe is positioned at the skin surface adjacent to the specific muscle of interest. Information about glycogen is obtained from the spectral resonance that corresponds to the $1-{ }^{13} \mathrm{C}$ of glucose in the glycogen-bound form. The integral area beneath this resonance is a direct indication of the number of $1{ }^{13} \mathrm{C}$ of glucose present in the glycogen-bound form. Chemical concentrations of glycogen are determined by comparing each human in vivo spectrum with a spectrum obtained from an external standard solution of known glycogen concentration (150-200 mmol/l). These values agree well with the values obtained by direct biochemical assay of muscle samples obtained from the same human subject and on the same day (Taylor et al. 1992). In these studies, uniform positioning of the probe and the subject was verified with magnetic resonance imaging, and ${ }^{13} \mathrm{C}$ NMR signals were obtained in natural abundance, which is only $1.1 \%$. When necessary, the ${ }^{13} \mathrm{C}$ signal strength can be increased by totally $1-{ }^{13} \mathrm{C}$-enriched glucose, which will increase the ${ }^{13} \mathrm{C}$ signal by a factor of approximately 100. Even increasing the $1{ }^{13} \mathrm{C}$ signal by a factor of 10 extends the sensitivity significantly at a modest cost.

The quantifiable visibility of glycogen was established by Sillerud \& Shulman (1983) when ${ }^{13} \mathrm{C}$ NMR spectra of glycogen in solution gave sharp resonances from approximately $100 \%$ of the $\mathrm{C}$ nuclei. A subsequent study demonstrated that these resonances were also visible in the perfused rat liver (Shulman et al. 1988). Proof of the visibility has been necessary because a macromolecule the size of glycogen would not give sharp visible lines if it were rigid. In subsequent NMR studies it was demonstrated that the large glycogen molecules had extensive internal motion (Zang et al. 1990a,b). A subsequent study demonstrated that muscle glycogen was $100 \%$ visible in a skinned rabbit muscle preparation (Gruetter et al. 1991). In a human population, an NMR validation study focused on repetitive 5 min measurements of the same muscle to evaluate reproducibility (Taylor et al. 1992). The study reported a $\mathrm{CV}$ that was $4.3 \%$, which for the basal muscle glycogen level of approximately $80 \mathrm{mmol} / \mathrm{l}$ was $\pm 3.4 \mathrm{mmol} / \mathrm{l}$ (Taylor et al. 1992). As expected, the accuracy of these measurements depended on the NMR signal:noise value, which improved as the square root of the time of measurement. Several measurements with $20 \mathrm{~min}$ of acquisition have yielded the expected twofold smaller CV (Price et al. 1991). However, the validation study had shown that even $5 \mathrm{~min}$ data acquisitions possessed an accuracy that was significantly better than that reported from biopsy measurements (Taylor et al. 1992). During these experiments it became clear that the errors were due to the signal:noise value of the NMR spectra, and that no additional uncertainties were introduced when the subjects left the magnet between measurements. Since optimum data acquisition conditions of magnet shimming and probe tuning could be reached within several minutes, there were no serious disadvantages in allowing the subject to leave the magnet between data acquisitions. As suitable NMR equipment has become available, well-resolved ${ }^{13} \mathrm{C}$ resonances have been regularly observed in vivo in both animal and human muscle and liver (Shulman et al. 1990; Price et al. 1994a; Taylor et al. 1996). 


\section{Exercise studies of muscle metabolism}

The initial application of ${ }^{13} \mathrm{C}$ NMR to human exercise studies was a measurement of glycogen levels in the gastrocnemius muscles of two athletic males before and after they ran a half-marathon (Avison et al. 1988). These results showed a $70 \%$ decrease in the muscle glycogen concentration and the depleted muscle glycogen returned to $80 \%$ of baseline during the next $19 \mathrm{~h}$ (Fig. 1). While the initial exercise experiment employed an exercise protocol (Avison et al. 1988) that resulted in substantial changes in systemic variables (e.g. blood glucose, lactate and $\mathrm{pH}$ ), subsequent studies have employed a localized-exercise protocol (Price et al. 1991, 1994a,b). Localized exercise buffers the systemic response for the study of glycogen metabolism by NMR. The results obtained from localized muscle measurements are consistent with the idea that during a localized-exercise protocol glycogen synthesis in the exercised muscle is under local control. The pathways of glucose uptake and glycogen metabolism are pictured schematically in Fig. 2. Glucose transported into the muscle that is increased as the result of exercise or insulin stimulation is phosphorylated by hexokinase ( $E C$ 2.7.1.1) to G6P and then incorporated into muscle glycogen (via two intermediates) or used directly by the muscle to generate energy via glycolysis.

In early studies muscle glycogen change was examined with localized low-intensity exercise of the gastrocnemius muscle (workloads of 15-25\% maximum voluntary contraction for the gastrocnemius muscle; Price et al. 1991, $1994 b$ ). Previous biopsy studies had reported that during exercise of low-to-moderate intensity (Costill et al. 1973) an initial period of glycogen depletion is followed by a period of constant glycogen levels despite continued exercise. In localized plantar flexion exercise $(15-25 \%$ maximum voluntary contraction) gastrocnemius glycogen declined for 2.5 (SE 0.5) $\mathrm{h}$ and then exhibited no further net decrease during $5.5 \mathrm{~h}$ of continued exercise (Price et al. 1991). This observation suggested an increased contribution from alternative $\mathrm{C}$ sources such as blood glucose or free fatty acids.

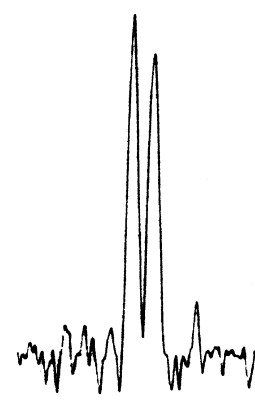

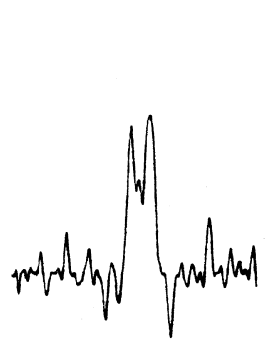

B

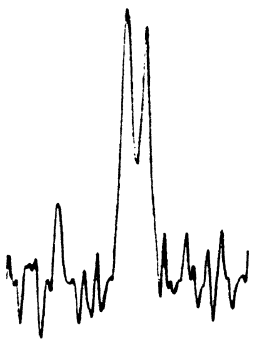

C
Fig. 1. The variation of intensity of the $\left[1^{13} \mathrm{C}\right]$ glycogen doublet (undecoupled spectrum) in response to exercise. Spectrum A was collected from the gastrocnemius muscle of a trained runner $1 \mathrm{~h}$ before a 13 mile run. Spectrum B was collected from the same location immediately after the run. Spectrum $\mathrm{C}$ was collected the following morning (19h after the run). These spectra, collected before natural-abundance ${ }^{13} \mathrm{C}$ NMR spectra were routinely decoupled, were presented in the initial report on the utility of NMR to detect exercise-induced changes in muscle glycogen. (From Avison et al. 1988; with permission.)
Although the net glycogen consumption ceased during this level period, the question remained as to whether the rates of glycogen synthesis and degradation both go to zero or whether these two pathways continue to be active resulting in turnover of the $\mathrm{C}$ in the muscle glycogen pool. This kind of turnover is known to occur in rat muscle and liver (Shulman et al. 1988; Hutber \& Bonen, 1989; David et al. 1990) and also in human (Magnusson et al. 1991, 1995) liver. However, there was no evidence that this energyexpensive process operates in individual human skeletal muscles. The plateau period of no net glycogen depletion could have resulted from cessation of glycogen depletion or from a dynamic steady-state in which glycogen synthesis and degradation rates matched one another. A subsequent study was performed in which $1-{ }^{13} \mathrm{C}$-labelled glucose was infused in order to increase the signal from glucose incorporation into glycogen and thus allow turnover of muscle glycogen to be detected during the plateau period (Price et al. 1994b). The results of that study indicated that there was turnover of glycogen within an individual muscle that was exercised for a prolonged period at a constant workload, and that turnover occurred during the previously-established plateau period of constant glycogen concentration (Costill et al. 1973; Constable et al. 1984; Price et al. 1991). In this localized-exercise protocol, infused $\left[1-{ }^{13} \mathrm{C}\right]$ glucose was incorporated into exercising muscle glycogen, but not into non-exercising muscle glycogen, during the infusion period. However, because the subjects stopped exercising while the ${ }^{13} \mathrm{C}$ NMR measurement was made, some uncertainty exists as to whether the glycogenesis occurred during the exercise or during the measurement. These experiments are currently being repeated with the NMR spectra acquired during exercise.

The methods employed in these localized-exercise and NMR studies consider the muscle as a whole and do not directly address the possibility that synthesis and degradation occur in different muscle fibres. Previous studies using exercise of large muscle groups had observed that at low-intensity workloads $\left(<45 \%\right.$ maximum $\mathrm{O}_{2}$ uptake) glycogen depletion in slow-twitch fibres preceded depletion in fast-twitch fibres (Gollnick et al. 1974; Vollestad \& Blom, 1985). Gollnick et al. (1974) demonstrated that after $3 \mathrm{~h}$ of pedalling exercise at $31 \%$ maximum $\mathrm{O}_{2}$ uptake almost all the $50 \%$ of muscle glycogen remaining in the human quadriceps femoris was in fast-twitch fibres. When $60 \%$ of the glycogen in that muscle remained $(2 \mathrm{~h}$ exercise) there was a significant amount present in slowtwitch fibres, although all slow-twitch fibres were partially depleted (Gollnick et al. 1974). Conversely, Ivy et al. (1987) reported that when the workload was moderate, all muscle fibres shared in contraction. Hence, the assessment of workload is of primary importance in understanding the results of this type of study.

More recent studies have examined the effect of an intense glycogen-depleting exercise protocol (50\% maximum voluntary contraction) on the period of recovery immediately following cessation of exercise. In the initial study of this series three exercise protocols (standing singleleg toe-raises) of different durations were performed, with intensities determined by the body weight of each subject (Price et al. 1994a). To reduce lactate accumulation in the 


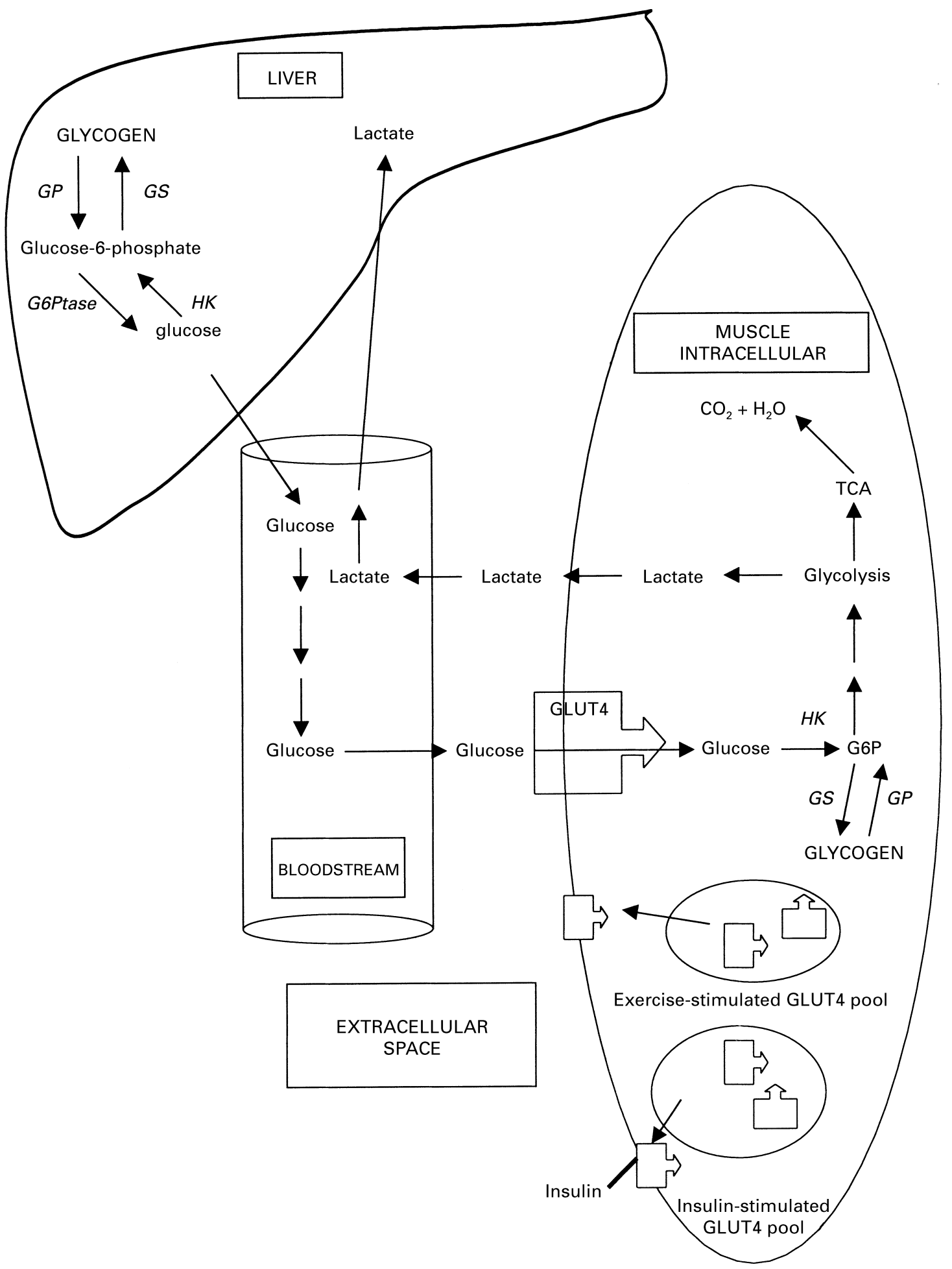

Fig. 2. Biochemical schematic of muscle and liver glycogen/glucose metabolism. Either insulin or exercise, or a combination of the two, may induce glucose transport via glucose transporter 4 (GLUT4) into muscle. Intramuscular glucose is then phosphorylated by hexokinase (EC 2.7.1.1; HK) into glucose-6-phosphate (G6P), and thereafter incorporated by glycogen synthase (EC 2.4.1.11; GS) into muscle glycogen. GP, glycogen phosphorylase (EC 2.4.1.1); TCA, tricarboxylic-acid cycle; G6Pase, glucose-6-phosphatase (EC 3.1.3.9).

muscle during exercise, subjects alternated toe-raises for 1 min (approximately thirty-five rises per min) with rest for $1 \mathrm{~min}$ throughout the exercise period. During exercise subjects maintained full extension of their knee in order to isolate the work. Based on assessment of maximal voluntary contraction, the mean workload was 51 (SE 5) \% maximum voluntary contraction (39-67\%). The exercise durations depleted glycogen in the gastrocnemius to approximately 
75,50 or $25 \%$ resting levels (11.3 (SE 1.8), 14.6 (SE 1.2), $26 \cdot 1$ (SE 3.5) min respectively; mean glycogen depletion rate 196 (SE 17) mmol/1 per h) assessed by natural abundance ${ }^{13} \mathrm{C}$ NMR spectroscopy (Price et al. 1994a). Plantar flexion exercise was performed from an erect standing position (single-leg toe raises) in order to selectively exercise the gastrocnemius. Total work values (kJ) were 22.1 (SE 4.9), 31.3 (SE 3.4), and 45.3 (SE 6.5) kJ respectively for depletion to 75,50 and $25 \%$ resting glycogen concentrations. The human gastrocnemius muscle is made up of approximately $60 \%$ slow-twitch (oxidative) fibres and approximately $40 \%$ fast-twitch (glycolytic) fibres. Although these fibre types are differentially recruited at light-to-moderate workloads, heavy exercise is known to deplete glycogen in all fibres (Ivy et al. 1987). Thus, it was assumed that the heavy load placed on the gastrocnemius in this exercise protocol recruited all fibres within the muscle (Ivy et al. 1987).

This localized-exercise protocol was used to study the effects of glycogen depletion and insulin concentration on glycogen synthesis. Gastrocnemius glycogen was measured with ${ }^{13} \mathrm{C}$ NMR before exercise and for $5 \mathrm{~h}$ following exercise. Subjects performed single-leg toe raises to deplete gastrocnemius glycogen to 75,50 or $25 \%$ resting concentration. After depletion to 75 and $50 \%$ resting levels, glycogen resynthesis rates were similar (2.4 (SE 0.7) and 2.8 (SE 0.6) mmol/1 per h respectively) as shown in Fig. 3 (Price et al. 1994a). When glycogen was depleted to $25 \%$ $(<30 \mathrm{mmol} / 1)$, the initial resynthesis rate was significantly higher $(P<0.02)$ at $33(\mathrm{SE} 7) \mathrm{mmol} / 1 \mathrm{per} \mathrm{h}$, and it declined to 3.5 (SE 0.9 ) $\mathrm{mmol} / 1 \mathrm{per} h$ at $>35 \mathrm{mmol}$ glycogen $/ 1$ (Price et al. 1994a). In the same study, insulin dependence of glycogen synthesis was assessed after depletion to $25 \%$ resting levels with and without infusion of somatostatin to inhibit insulin secretion (Price et al. 1994a). A subset of subjects ( $n$ 5) each depleted gastrocnemius glycogen to

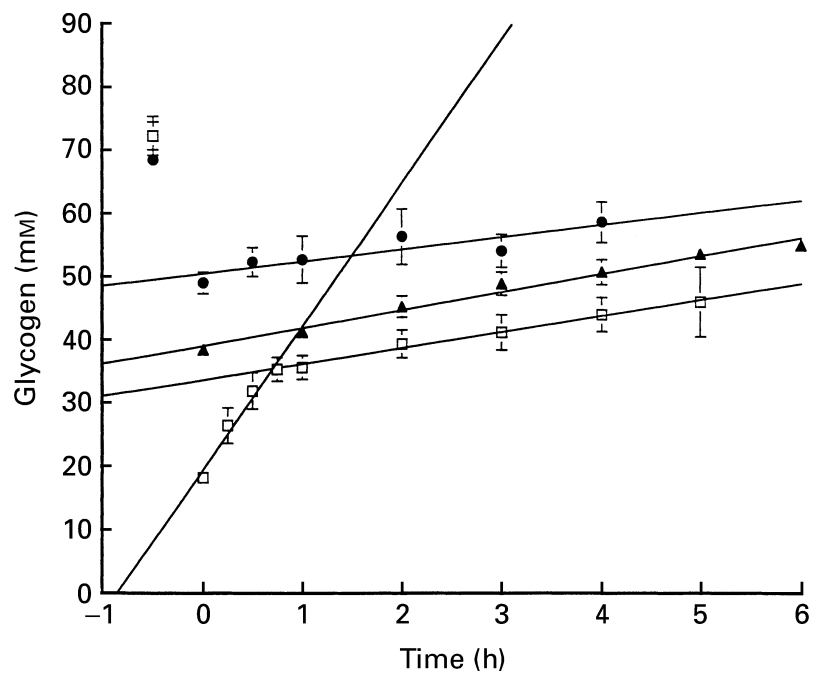

Fig. 3. Time-course of gastrocnemius muscle glycogen from depletion to $75(\bullet), 50(\boldsymbol{\Delta})$ and $25(\square) \%$ resting concentration. Values are means with their standard errors represented by vertical bars for three, eight and eight trials at 75, 50 and $25 \%$ resting glycogen concentrations respectively. (-), Linear regression analysis. At $25 \%$ resting glycogen the linear regression is split into two time periods (0-45 min and 1-6h) (From Price et al. 1994a; with permission.)
$25 \%$ resting levels in a paired study with and without infusion of somatostatin to suppress insulin release. At $<35 \mathrm{mmol} / 1$ glycogen synthesis was not significantly affected by low insulin (24 (SE 4) mmol/1 per h with insulin v. 19 (SE 3) $\mathrm{mmol} / 1$ per $\mathrm{h}$ without insulin), whereas at $>35 \mathrm{mmol}$ glycogen $/ 1$, synthesis ceased without insulin (3.3 (SE 0.8) $\mathrm{mmol} / 1$ per $\mathrm{h}$ with insulin $v$. -0.07 (SE 0.19) mmol/1 per h without insulin (Fig. 4; Price et al. 1994a). The study concluded that after depletion to $<30 \mathrm{mmol} / 1$ per $\mathrm{h}$ initial glycogen resynthesis was insulin independent, and concurred with the findings of Garetto et al. (1984) who reported two phases of glycogen recovery in the rat muscle following intense exercise, one of which was insulin dependent. It was also consistent with observations by Maehlum et al. (1977) on subjects with insulin-dependent diabetes mellitus who showed an early glycogen repletion that was independent of insulin. Since ${ }^{13} \mathrm{C}$ NMR studies have the advantage that synthesis rates can be measured more accurately over a longer time interval and with considerably better time resolution, the NMR study demonstrated a clear biphasic glycogen recovery pattern in normal human subjects (Price et al. 1994a).

An additional advantage to human in vivo NMR spectroscopy is the ability to study other NMR visible nuclei, particularly ${ }^{31} \mathrm{P}$. In an insulin-glucose clamp, ${ }^{31} \mathrm{P}$ NMR was used to determine G6P concentrations in the muscle in vivo (Rothman et al. 1992). Basal concentrations of G6P in the human gastrocnemius muscle were 0.12 (SE 0.01) mmol/1, which was several times lower than those sometimes reported from biopsies (Young et al. 1988; Rosetti \& Giaccari, 1990; Rothman et al. 1992). During the hyperinsulinaemic-hyperglycaemic clamp ${ }^{31} \mathrm{P}$ NMR measured an increase in G6P concentration in the gastrocnemius muscle. Difference spectra showed wellresolved increases in intensity in the low-field portion of the phosphomonoester regions of the spectrum at positions that were identified as G6P (Fig. 5; Rothman et al. 1992). In an earlier study an increase in spectral intensity was found at the chemical shift characteristic of the ${ }^{31} \mathrm{P}$ resonance of G6P

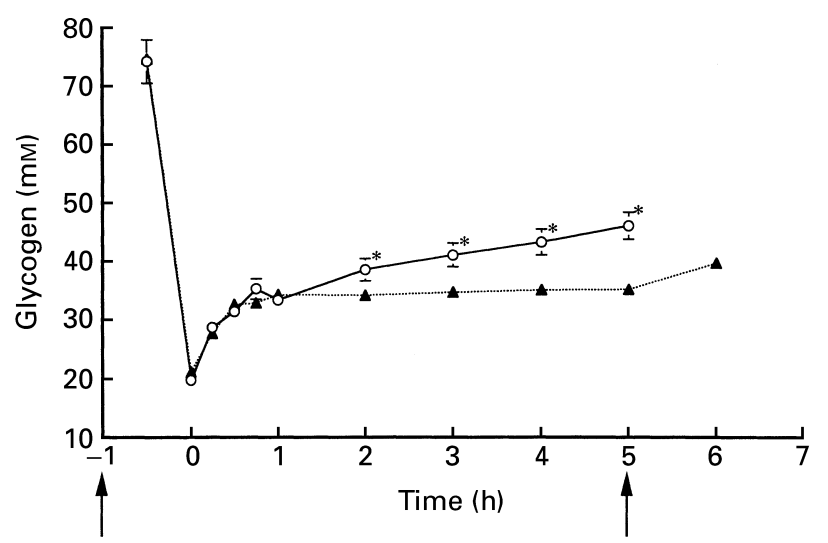

Fig. 4. Paired study of glycogen recovery from depletion to $25 \%$ resting concentration under conditions of inhibited insulin $(\boldsymbol{A})$ with infusion of somatostatin, and under normal insulin conditions $(\bigcirc)$ without somatostatin. Values are means with their standard errors represented by vertical bars for five paired trials. $\uparrow$, Beginning and end of somatostatin infusion. At $2 \mathrm{~h}$ into the recovery period, mean glycogen concentrations were significantly lower in the insulin-inhibited group ( ${ }^{*} \leq 0.01$ ). (From Price et al. 1994a; with permission.) 
following human forearm exercise (Pan et al. 1989); however, in contrast to the simple increase in the ${ }^{31} \mathrm{P}$ spectra seen during the hyperinsulinaemic-hyperglycaemic clamp, the changes in the phosphomonoester region after intense exercise were more complex. With these assignments it was possible to measure the rates of glycogen synthesis $\left(\right.$ by ${ }^{13} \mathrm{C}$ NMR) and the G6P concentrations (by ${ }^{31} \mathrm{P}$ NMR) simultaneously in the rat gastrocnemius after intense glycogendepleting exercise (Bloch et al. 1994). NMR with its unique ability to examine non-invasively muscle G6P (with ${ }^{31} \mathrm{P}$ ) and glycogen (with ${ }^{13} \mathrm{C}$ ) simultaneously with interleaved pulse sequences, was therefore an ideal combination method for assessment of exercise effects on glycogen synthesis in a human population.

Since the initial intense glycogen-depleting exercise study demonstrated that in normal healthy human subjects there was an early phase of rapid glycogen resynthesis (12-30 mmol/l per h) lasting approximately $45 \mathrm{~min}$ that was insulin independent and a subsequent period of glycogen resynthesis (above approximately $35 \mathrm{mmol}$ glycogen/l) that was much slower (approximately $3 \mathrm{mmol} / \mathrm{l}$ per $\mathrm{h}$ ) and insulin dependent (Price et al. 1994a), a second exercise study compared control subjects with the insulin-resistant offspring of parents with non-insulin-dependent diabetes mellitus (NIDDM; Price et al. 1996). During the insulinindependent portion of recovery from glycogen-depleting exercise the glycogen recovery rates were not significantly different between the control and the insulin-resistant groups (Fig. 6). However, during the insulin-dependent portion of muscle glycogen resynthesis the control subjects synthesized glycogen at a rate of $2.9(\mathrm{SE} 0.2) \mathrm{mmol} / \mathrm{l}$ per $\mathrm{h}$,
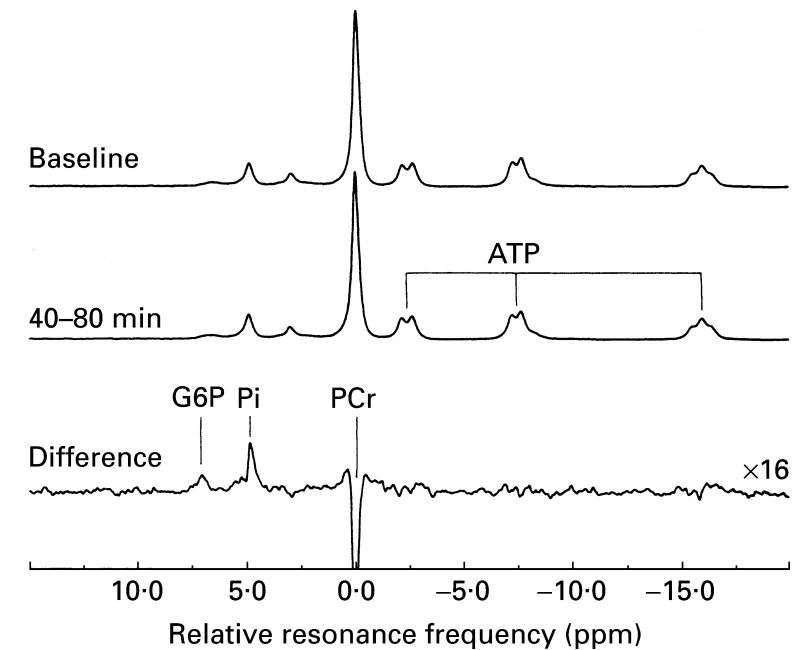

Fig. 5. ${ }^{31} \mathrm{P}$ NMR spectra of the gastrocnemius muscle of a normal subject. A baseline spectrum and a spectrum acquired over the period of $40-80 \mathrm{~min}$ into a low-dose insulin clamp are shown, as well as the difference between these two spectra. In the difference spectrum (clamp minus baseline), an increase during the clamp is observed of the resonances of glucose-6-phosphate (G6P; 7.13 parts per $\left.10^{6}(\mathrm{ppm})\right)$ and inorganic phosphate ( $\left.\mathrm{Pi} ; 4.88 \mathrm{ppm}\right)$. The increase is quantitatively accounted for by a decrease in phosphocreatine (PCr; $0.00 \mathrm{ppm}$ ), which is not completely shown in the plot owing to its greater resonance amplitude. The increase in the G6P resonance intensity corresponds to a $0.13 \mathrm{mmol} / \mathrm{l}$ muscle increase in concentration. (From Rothman et al. 1992; with permission.) while the insulin-resistant subjects showed a negligible rate of muscle glycogen synthesis (0.1 (SE 0.5) mmol/l per h; Fig. 6). This difference in synthesis occurred despite similar plasma concentrations of glucose and higher concentrations of insulin (Price et al. 1996). The reduced rate of muscle glycogen synthesis during this period may have been due to an insulin dependent impairment of either glucose transport and subsequent phosphorylation, or glycogen synthase (EC 2.4.1. 11). The mean of the G6P data was not significantly different from that for the control subjects, and was similar to pre-exercise values during the insulin-dependent phase. The finding of similar G6P concentration with decreased glycogen synthesis suggests that both glucose transport and subsequent phosphorylation, and glycogen synthase activity are reduced in a coordinated manner.

Exercise and insulin are both known to stimulate muscle glucose uptake and subsequent glycogen synthesis
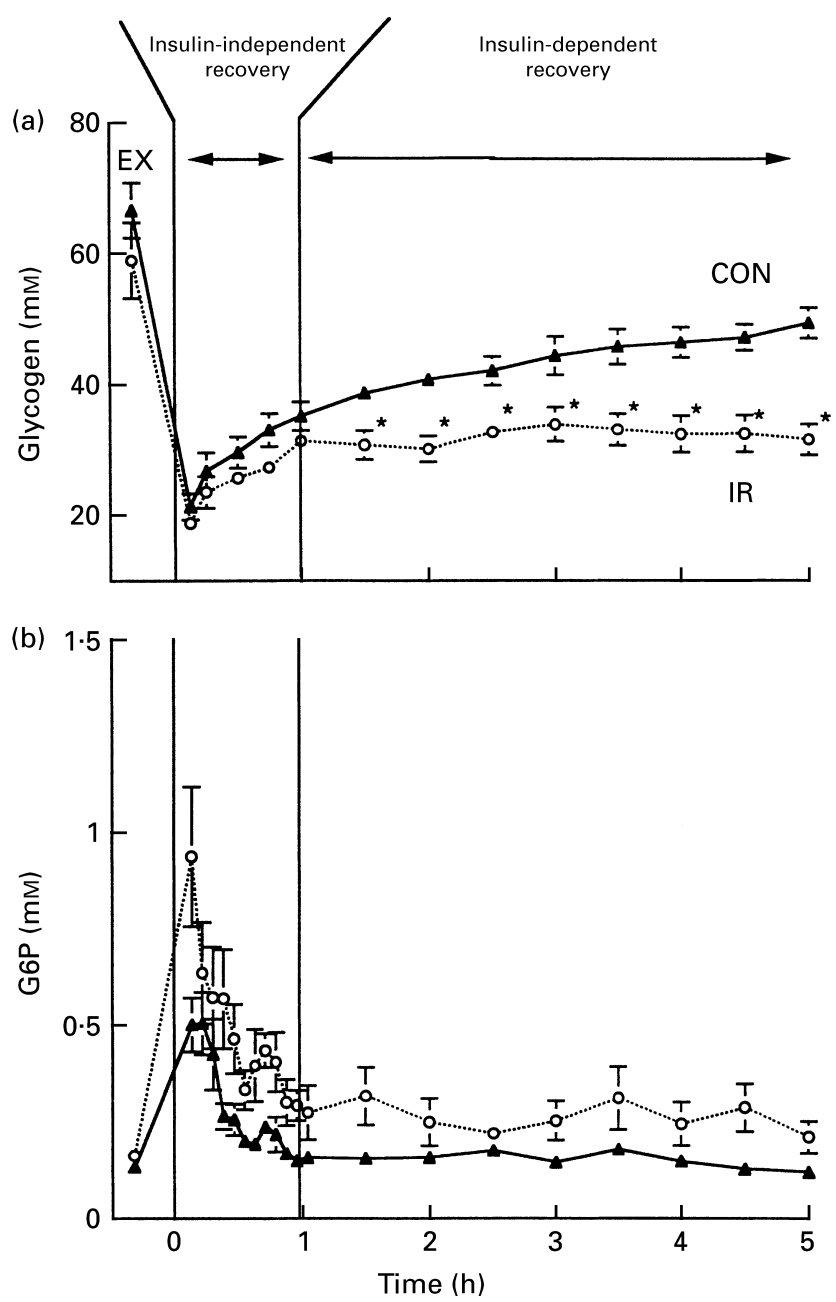

Fig. 6. Time-courses of (a) glycogen and (b) glucose-6-phosphate (G6P) concentration before, during a single-leg toe-raise exercise protocol (EX), and during $5 \mathrm{~h}$ recovery of glycogen-depleted gastrocnemius muscles in age- and weight-matched control $(\mathrm{CON} ; \mathbf{\Delta})$ and insulin-resistant $(\mathrm{IR} ; \mathrm{O})$ offspring of parents with adult-onset diabetes mellitus. Values are means with their standard errors represented by vertical bars for eight trials for each group. The insulin-dependent phase of muscle glycogen recovery was significantly impaired in the $\operatorname{IR}$ group ( $\left.{ }^{*} P \leq 0.05\right)$. (From Price et al. 1996; with permission.) 
in an independent and additive manner (Roch-Norland $e$ t al. 1972; Wallberg-Henriksson et al. 1988; Sternlicht et al. 1989; Douen et al. 1990; Goodyear et al. 1990). Under resting conditions the effect of insulin stimulation on glycogen synthesis has been compared in healthy control subjects and in subjects with NIDDM by ${ }^{13} \mathrm{C}$ NMR (Shulman et al. 1990). In both control subjects and subjects with NIDDM placed under hyperglycaemichyperinsulinaemic conditions the major pathway of insulindependent glucose metabolism was muscle glycogen synthesis (Shulman et al. 1990). However, in the subjects with NIDDM the rate of muscle glycogen synthesis was significantly slower (Shulman et al. 1990). Fig. 6 demonstrates that following muscle-glycogen-depleting exercise the insulin-resistant offspring of parents with NIDDM had: (1) normal rates of muscle glycogen synthesis and intracellular G6P concentrations during the early insulin-independent phase of recovery from exercise; (2) severely diminished rates of muscle glycogen synthesis during the subsequent recovery period $(2-5 \mathrm{~h})$ which had been shown to be insulin dependent in normal control subjects (Price et al. 1996). The data provided evidence that exercise and insulin stimulate muscle glycogen synthesis in human subjects by different mechanisms, and that in the insulin-resistant subjects the early response to stimulation by exercise is normal. The results of this study therefore support the existence of distinct mechanisms for exercise and insulin action on the glucose transport step, since normal glucose transport was present in the insulin-resistant subjects following exercise, despite their previously demonstrated impairment of insulin-stimulated glucose transport and subsequent phosphorylation (Shulman et al. 1990).

\section{Muscle and liver glycogen turnover following a mixed meal}

A knowledge of carbohydrate storage after a mixed meal is of paramount importance in understanding normal energy metabolism in human subjects. The non-invasive nature of ${ }^{13} \mathrm{C}$ NMR has allowed postprandial glycogen storage to be studied in both muscle and liver (Taylor et al. 1993, 1996; Hwang et al. 1995; Petersen et al. 1996). When the combined data of muscle and liver studies are examined, distinct patterns that occur over the first $7 \mathrm{~h}$ following a mixed meal can be distinguished. In all studies a mixed meal was consumed (zero time) following an overnight fast (at least $10 \mathrm{~h}$ ). The increase in liver glycogen peaked 5-6h after the meal, with glycogen increasing from $277 \mathrm{mmol} / \mathrm{l}$ immediately before the meal to a high of $438 \mathrm{mmol} /$ litre $6 \mathrm{~h}$ after the meal (Hwang et al. 1995; Petersen et al. 1996; Taylor et al. 1996). Liver glycogen declined by $30 \mathrm{mmol} / \mathrm{l}$ (to a value of $408 \mathrm{mmol} / \mathrm{l}$ ) by $7 \mathrm{~h}$ after the meal, and returned to resting levels at $15 \mathrm{~h}$ after the meal (Petersen et al. 1996; Taylor et al. 1996), despite an approximately $50 \%$ contribution to hepatic glucose production by gluconeogenesis (Petersen et al. 1996).

Muscle glycogen, measured in the gastrocnemius, reached a peak between 4 and $6 \mathrm{~h}$ after a mixed meal. The greatest increase in muscle glycogen concentration was
$17 \mathrm{mmol} / \mathrm{l}$ at $4.9 \mathrm{~h}$, with a subsequent decline of about $10 \mathrm{mmol} / \mathrm{l}$ between 6 and $7 \mathrm{~h}$ (Taylor et al. 1993). Blood glucose levels peaked at $144 \%$ resting levels $30 \mathrm{~min}-1 \mathrm{~h}$ after the meal, declined to $112 \%$ resting values at $2 \mathrm{~h}$, and then slowly increased to $120 \%$ resting levels over the next $2 \mathrm{~h}$ (4 h after the meal; Taylor et al. 1993, 1996; Hwang et al. 1995). From $4 \mathrm{~h}$ to $7 \mathrm{~h}$ blood glucose steadily declined to reach $111 \%$ resting levels at $7 \mathrm{~h}$ after the meal. The changes in blood glucose and liver and muscle glycogen during the first $7 \mathrm{~h}$ after a mixed meal are shown in Fig. 7 . In order to compare data from the muscle and liver studies, values are given as a percentage of resting levels with resting levels normalized to $100 \%$. When viewed in this way the interplay between the three variables can be seen, with blood glucose triggering a global synthesis of glycogen over the first 4-6 h following the meal and then global glycogen utilization occurring from $6-7 \mathrm{~h}$. When a standard $70 \mathrm{~kg}$ man is used as a model, it can be assumed that muscle comprises approximately $500 \mathrm{~g} / \mathrm{kg}$ body mass $(35 \mathrm{~kg})$. Liver mass is approximately $1.5 \mathrm{~kg}$ (or $21 \mathrm{~g} / \mathrm{kg}$ total body mass; Petersen et al. 1996). If it is assumed that glycogen increases in the gastrocnemius are representative of the total body musculature, then the relative contributions of liver and muscle to glucose disposal can be estimated. Employing these assumptions, approximately $70 \%$ of the glucose consumed in a mixed meal is stored in muscle, and when gluconeogenesis is considered the percentage increases to more than $80 \%$.

In summary, the non-invasive nature of ${ }^{13} \mathrm{C}$ NMR now allows the routine study of muscle and liver glycogen. Studies of muscle recovery from exercise have been performed, as well as studies of the effect of a mixed meal on muscle and liver glycogen storage. Since the ${ }^{13} \mathrm{C}$ techniques can be combined with other NMR measurements, such as ${ }^{31} \mathrm{P}$ and ${ }^{1} \mathrm{H}$, the possibility now exists to obtain non-invasively and simultaneously data relating to a number of energy metabolites. With this combined information, metabolic studies that were previously impossible are now accessible in a number of different populations.

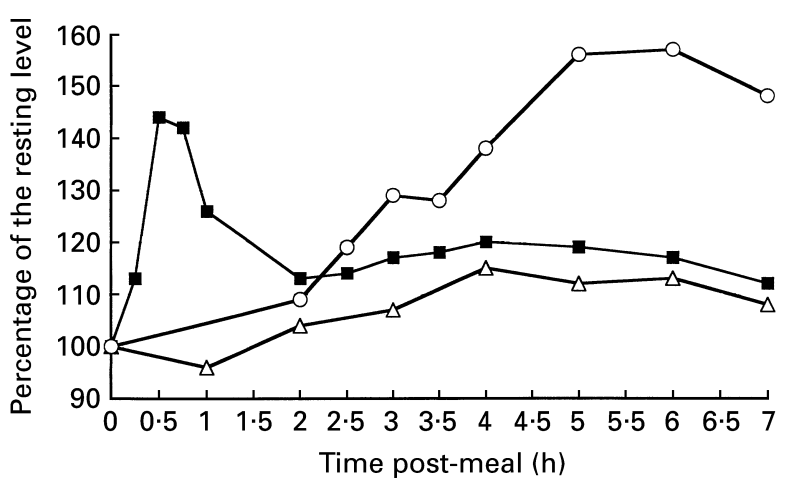

Fig. 7. Percentage of the resting concentration for blood glucose $(\square)$, liver glycogen $(\bigcirc)$, and muscle glycogen $(\triangle)$ over the first $7 \mathrm{~h}$ following consumption of a mixed meal $(300 \mathrm{~g}$ containing $(\mathrm{g} / \mathrm{kg})$ 500 carbohydrate, 300 fat, 200 protein). Subject populations were normal healthy male and female, aged 18-40 years, without a family history of diabetes (From Price \& Rothman, 1999; with permission.) 


\section{Acknowledgements}

This article, and its precursor, has profited from considering a question raised by Dr Coggan about muscle glycogen turnover. In its present form, it is a modified version of the review by Price \& Rothman (1999).

\section{References}

Avison MJ, Rothman DL, Nadel E, Jue T \& Shulman RG (1988) Detection of human muscle glycogen by natural abundance ${ }^{13} \mathrm{C}$ NMR. Proceedings of the National Academy of Sciences USA 85, $1634-1636$

Bloch G, Chase JR, Meyer DB, Avison MJ, Shulman GI \& Shulman RG (1994) In vivo regulation of rat muscle glycogen resynthesis after intense exercise. American Journal of Physiology 266, E85-E91.

Constable SH, Young JC, Highuchi M \& Holloszy JO (1984) Glycogen resynthesis in leg muscles of rats during exercise. American Journal of Physiology 247, R880-R883.

Costill DL, Gollnick PD, Jansson ED, Saltin B \& Stein EM (1973) Glycogen depletion pattern in human muscle fibres during distance running. Acta Physiologica Scandinavica 89, 374-383.

David M, Petit WA, Laughlin MR, Shulman RG, King JE \& Barrett EJ (1990) Simultaneous synthesis and degradation of rat liver glycogen. Journal of Clinical Investigation 86, 612-617.

Dietrichson P, Coakley J, Smith PEM, Griffiths RD, Helliwell TR $\&$ Edwards RHT (1987) Conchotome and needle percutaneous biopsy of skeletal muscle. Journal of Neurology and Neurosurgery 50, 1461-1467.

Douen AG, Ramlal T, Pastogi S, Bilan PJ, Cartee GD, Vranic M, Holloszy JO \& Klip A (1990) Exercise induces recruitment of the 'insulin-responsive glucose transporter'. Journal of Biological Chemistry 265, 13427-13430.

Gadian DG, Radda GK, Richards RE \& Seeley PJ (1979) P-31 NMR in living tissue: The road from a promising tool to an important tool in biology. In Biological Applications of Magnetic Resonance, pp. 463-536 [RG Shulman, editor]. New York: Academic Press Inc.

Garetto LP, Richter EA, Goodman MN \& Ruderman NB (1984) Enhanced muscle glucose metabolism after exercise in the rat: the two phases. American Journal of Physiology 246, E471-E475.

Gollnick PD, Piehl K \& Saltin B (1974) Selective glycogen depletion pattern in human muscle fibres after exercise of varying intensity and at varying pedalling rates. Journal of Physiology 241, 45-57.

Goodyear LJ, Hirshman MF, King PA, Horton ED, Thompson CM \& Horton ES (1990) Skeletal muscle plasma membrane glucose transport and glucose transporters after exercise. Journal of Applied Physiology 68, 193-198.

Gruetter R, Prolla TA \& Shulman RG (1991) ${ }^{13}$ C NMR visibility of rabbit muscle glycogen in vivo. Magnetic Resonance in Medicine 20, 327-332.

Harris RC, Hultman E \& Nordesjo LO (1974) Glycogen, glycolytic intermediates and high-energy phosphates determined in biopsy samples of musculus quadriceps femoris of man at rest: Methods and variance of values. Scandinavian Journal of Clinical and Laboratory Investigation 33, 109-120.

Hutber CA \& Bonen A (1989) Glycogenesis in muscle and liver during exercise. Journal of Applied Physiology 66, 2811-2817.

Hwang JH, Perseghin G, Rothman DL, Cline GW, Magnusson I, Petersen KF \& Shulman GI (1995) Impared net hepatic glycogen synthesis in insulin-dependent diabetic subjects during mixed meal ingestion. Journal of Clinical Investigation 95, 783-787.
Ivy JL, Chi MM-Y, Hintz CS, Sherman WM, Hellendal RP \& Lowry OH (1987) Progressive metabolite changes in individual human muscle fibers with increasing work rates. American Journal of Physiology 252, C630-C639.

Jue T, Rothman DL, Tavitian BA \& Shulman RG (1989) Naturalabundance ${ }^{13} \mathrm{C}$ NMR study of glycogen repletion in human liver and muscle. Proceedings of the National Academy of Sciences USA 86, 1439-1442.

Maehlum S, Hostmark AT \& Hermansen L (1977) Synthesis of muscle glycogen during recovery after severe exercise in diabetic and non-diabetic subjects. Scandinavian Journal of Clinical and Laboratory Investigation 37, 309-316.

Magnusson I, Rothman DL, Gerard DP, Katz LD \& Shulman GI (1995) Hepatic glycogenolysis during glucagon infusion in humans. Diabetes 44, 185-189.

Magnusson I, Rothman DL, Jucker B, Shulman RG \& Shulman GI (1991) ${ }^{13} \mathrm{C}$ NMR studies of liver glycogen turnover in fed and fasted man. Diabetes 40, Suppl., 300.

Pan JW, Hamm JR, Rothman DL \& Shulman RG (1989) In vivo titration of phosphomonoesters by H-1 decoupled P-31 NMR in human skeletal muscle after exercise. Proceedings of the Society of Magnetic Resonance in Medicine Annual Meeting, 542.

Petersen KF, Price TB, Cline GW, Rothman DL \& Shulman GI (1996) Contribution of net hepatic glycogenolysis to glucose production during the early postprandial period. American Journal of Physiology 270, E186-E191.

Price TB, Perseghin G, Duleba A, Chen W, Chase J, Rothman DL, Shulman RG \& Shulman GI (1996) NMR studies of muscle glycogen synthesis in insulin resistant offspring of NIDDM parents immediately following glycogen depleting exercise. Proceedings of the National Academy of Sciences USA 93, 5329-5334.

Price TB \& Rothman DL (1999) Tracking human muscle and liver metabolism non-invasively with carbon-13 NMR. In Adaptation Biology and Medicine, vol. 2, pp. 200-213 [BB Pandolf, N Takeda and PK Singal, editors]. New Dehli, India: Narosa Publishing House.

Price TB, Rothman DL, Avison MJ, Buonamico P \& Shulman RG (1991) ${ }^{13} \mathrm{C}$ NMR measurements of muscle glycogen during low intensity exercise. Journal of Applied Physiology 70, 1836-1844.

Price TB, Rothman DL, Taylor R, Shulman GI, Avison MJ \& Shulman RG (1994a) Human muscle glycogen resynthesis after exercise: insulin dependent and independent phases. Journal of Applied Physiology 76, 104-111.

Price TB, Taylor R, Mason GM, Rothman DL, Shulman GI \& Shulman RG (1994b) Turnover of human muscle glycogen during low-intensity exercise. Medicine and Science in Sports and Exercise 26, 983-991.

Robergs RA, Pearson DR, Costill DL, Fink WJ, Pascoe DD, Benedict MA, Lambert CP \& Zachweija JJ (1991) Muscle glycogenolysis during differing intensities of weight-resistance exercise. Journal of Applied Physiology 70, 1700-1706.

Roch-Norlund AE, Bergstrom J \& Hultman E (1972) Muscle glycogen and glycogen synthetase in normal subjects and in patients with diabetes mellitus. Scandinavian Journal of Clinical and Laboratory Investigation 30, 77-84.

Rosetti L \& Giaccan A (1990) Relative contribution of glycogen synthesis and glycolysis to insulin mediated glucose uptake: a dose response study. Journal of Clinical Investigation 85, $1785-1792$.

Rothman DL, Magnusson I, Katz LD, Shulman RG \& Shulman GI (1990) Quantitation of hepatic glycogenolysis and gluconeogenesis in fasting humans using C-13 NMR. Science 254, $573-576$

Rothman DL, Shulman RG \& Shulman GI (1992) P-31 NMR measurements of muscle glucose-6-phosphate: evidence for 
reduced insulin dependent muscle glucose transport or phosphorylation in non-insulin dependent diabetes. Journal of Clinical Investigation 89, 1069-1075.

Shulman GI, Rothman DL, Chung Y, Rossetti L, Petit WA, Barrett EJ \& Shulman RG (1988) ${ }^{13}$ C NMR studies of glycogen turnover in the perfused rat liver. Journal of Biological Chemistry 263, 5027-5029.

Shulman GI, Rothman DL, Jue T, Stein P, DeFronzo RA \& Shulman RG (1990) Quantitation of muscle glycogen synthesis in normal subjects and subjects with non-insulin dependent diabetes mellitus by ${ }^{13} \mathrm{C}$ nuclear magnetic resonance spectroscopy. New England Journal of Medicine 322, 223-228.

Sillerud GI \& Shulman RG (1983) Structure and metabolism of mammalian liver glycogen monitored by carbon-13 nuclear magnetic resonance. Biochemistry 22, 1087-1094.

Sternlicht E, Barnard RJ \& Grimditch GK (1989) Exercise and insulin stimulate skeletal muscle glucose transport through different mechanisms. American Journal of Physiology 256, E227-E230.

Taylor R, Magusson I, Rothman DL, Cline GW, Caumo A, Cobelli C \& Shulman GI (1996) Direct assessment of liver glycogen storage by ${ }^{13} \mathrm{C}$ nuclear magnetic resonance spectroscopy and regulation of glucose homeostasis after a mixed meal in normal subjects. Journal of Clinical Investigation 97, 126-132.
Taylor R, Price TB, Katz LD, Shulman RG \& Shulman GI (1993) Direct measurement of change in muscle glycogen concentration after a mixed meal in normal subjects. American Journal of Physiology 265, E224-E229.

Taylor R, Price TB, Rothman DL, Shulman RG \& Shulman GI (1992) Validation of ${ }^{13} \mathrm{C}$ NMR measurement of human skeletal muscle glycogen by direct biochemical assay of needle biopsy samples. Magnetic Resonance in Medicine 27, 13-20.

Vollestad NK \& Blom PCS (1985) Effect of varying exercise intensity on glycogen depletion in human muscle fibres. Acta Physiologica Scandinavica 125, 395-405.

Wallberg-Henriksson H, Constable SH, Young DA \& Holloszy JO (1988) Glucose transport into rat skeletal muscle: interaction between exercise and insulin. Journal of Applied Physiology 65, 909-913.

Young AA, Bogardus C, Stone K \& Mott DM (1988) Insulin responses of components of whole-body and muscle carbohydrate metabolism in humans. American Journal of Physiology E231-E236.

Zang L-H, Laughton MR, Rothman DL \& Shulman RG (1990a) ${ }^{13} \mathrm{C}$ NMR relaxation times of hepatic glycogen in vitro and in vivo. Biochemistry 29, 6815-6820.

Zang L-H, Rothman DL \& Shulman RG (1990b) ${ }^{1} \mathrm{H}$ NMR visibility of mammalian glycogen in solution. Proceedings of the National Academy of Sciences USA 87, 1678-1680. 